\title{
From Principals' Inspirational Vision Content and Potential Absorptive Capacity to Realized Absorptive Capacity: Predicting Teacher Absenteeism
}

\author{
Rima'a Da'as ${ }^{1, *} \&$ Mowafaq Qadach ${ }^{2}$ \\ ${ }^{1}$ Al- Qasemi- Academic College of Education, Baqa- El- Garbia, Israel \\ ${ }^{2}$ Ono Academic College, Kiryat Ono, Israel \\ *Correspondence: Al- Qasemi- Academic College of Education, Baqa- El- Garbia, Israel. E-mail: \\ rimaajd@gmail.com
}

Received: March 26, 2018

Accepted: April 10, $2018 \quad$ Online Published: April 17, 2018

doi:10.5430/wje.v8n2p140

URL: https://doi.org/10.5430/wje.v8n2p140

\begin{abstract}
This paper builds upon the theoretical framework developed by Zahra and George (2002) to empirically explore, first, the moderator effect of principals' inspirational vision content as a social mechanism that reduces the gap between potential absorptive capacity (PACAP; the ability to acquire and assimilate external knowledge) and realized absorptive capacity (RACAP; the ability to transform and exploit this external knowledge to school processes); and second, the relationship between RACAP and long-term school outcomes (teachers' absenteeism 1 year later). Based on a sample of 600 teachers from 100 elementary schools in Israel, results showed that the relationship between PACAP and RACAP is not conditioned by principals' inspirational vision content. The latter and PACAP predicted RACAP separately. Further, RACAP was negatively correlated with teacher absenteeism. This study provides a deeper understanding of the ACAP model in the school context and opens new avenues to exploring the social integration mechanism between PACAP and RACAP. It also adds a new construct to predict teacher absenteeism over the long term.
\end{abstract}

Keywords: inspirational vision content, potential absorptive capacity, realized, absenteeism

\section{Introduction}

School is an inherently complex organization, involving myriad interacting activities, people, and purposes. The complexity of the school environment ensures focused attention on knowledge as a dominant source of competitive advantage and school effectiveness (Da'as, 2007). Researchers have argued that organizations need to recognize new external knowledge, assimilate it, and apply it to organizational processes (Volberda et al., 2010). This ability is referred to as absorptive capacity (ACAP) (Cohen \& Levinthal, 1990). Organizations endowed with greater ACAP are expected to outperform others (Cassiman \& Veugelers, 2002; Zollo \& Winter, 2002), through increased performance and effectiveness (Khanet al., 2017), and through feeding of the internal innovation process which becomes a crucial source of competitive advantage (Easterby-Smith \& Lyles, 2003). Specifically, ACAP is considered to be a type of organizational learning (Lane et al., 2006). It draws attention to the need to appreciate and acquire knowledge from the external environment, while simultaneously focusing on internal processes of learning from past experience and current actions (Easterby-Smith et al., 2008). Organizational learning is a critical component in achieving school effectiveness, and schools that function as learning organizations perform better than those that do not (e.g., Mulford \& Silins, 2011).

We adopted Zahra and George's (2002) conceptualization of ACAP as organizational processes through which organizations acquire, assimilate, transform, and exploit knowledge, to create a competitive advantage. Zahra and George (2002) suggested that ACAP exists as two subsets of potential and realized ACAP. Potential ACAP (PACAP) comprises knowledge acquisition and assimilation capabilities and realized ACAP (RACAP) centers on knowledge transformation and exploitation.

The identification of ACAP as a dynamic capability, a key factor in organizational learning (e.g., Lane et al., 2006; Saraf et al., 2013) and facilitating innovative behavior (Kang \& Lee, 2017), and an essential element for innovation 
in schools and in adapting to changes in the competitive environment (e.g., Zinkeviciene, 2004), suggests essential research questions: What is the impact of school ACAP on the school's long-term outcomes (e.g., teacher absenteeism)? What is the role of the principal's vision content in facilitating the free flow of information and in allowing the school to transform and exploit this information? We address this issue by distinguishing PACAP from RACAP.

Zahra and George (2002) theorized that the relationship between PACAP and RACAP is moderated by social integration mechanisms. They said that such mechanisms "lower the barriers to information sharing while increasing the efficiency of assimilation and transformation capabilities" (p. 194).

Researchers have argued that leaders need a clear vision to encourage followers to acquire, assimilate, transform and exploit external knowledge, and to collectively think about and share information on an ongoing basis (Berson et al., 2015; Da'as, 2007). Specifically, the content of the vision is critical in encouraging followers to promote learning processes (Orhan et al., 2014), and in determining whether the leader will move in new directions while maintaining a high level of continued success (Berson et al., 2001). The vision content (i.e., vision or mission statement) for the organization can serve as a powerful vehicle in achieving shared understanding and support from employees for the firm's strategic road map (Stokely, 2004).

Consequently, we extend the work of integration mechanisms (Zahra \& George, 2002) by examining the use of principals' inspirational vision content (Berson et al., 2001) as a social integration mechanism that reduces the gap between PACAP and RACAP. Research on the connection between principals' inspirational vision content and PACAP and RACAP is still scarce, and the literature in this field highlights the need for additional research in this area (Phoocharoon, 2015; Volberda et al., 2010), specifically in the school context (Da'as, 2007).

Finally, recent research has focused on the role of ACAP in innovation (e.g., Kang \& Lee, 2017), intra-organizational knowledge transfer and organizational learning (e.g., Saraf et al., 2013), and business performance (e.g., Khan et al., 2017). However, the relations between ACAP and absenteeism have never been examined (Da'as, 2007). Teacher absenteeism has educational and behavioral effects on students, and previous research has indeed found a negative relationship between teacher absences and student achievement (e.g., Gbore \& Daramola, 2013; Miller et al., 2008). For example, Miller et al. (2008) looked at the impact of teacher absences on fourth-grade test scores in a large, urban school district and found that 10 days of teacher absences in 1year reduced mathematics achievement by $3.2 \%$ of a standard deviation (Miller et al., 2008). Thus, the current study examines whether a school's ability to absorb, assimilate, transform and exploit external knowledge will reduce teacher absenteeism 1 year after the ACAP has been established (Figure 1).

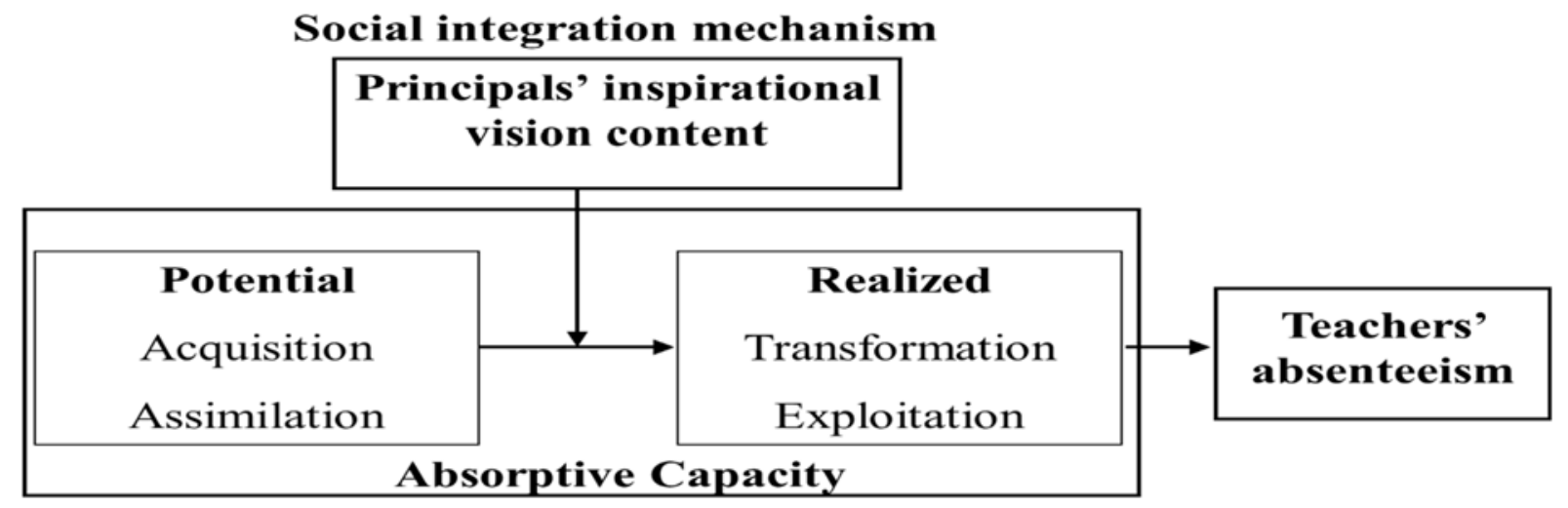

Figure 1. Hypothesized Model

\section{Theoretical Overview and Hypotheses}

\subsection{Dimensions of ACAP}

Zahra and George's (2002) conceptualization of ACAP suggested four distinct but complementary capabilities: acquisition, assimilation, transformation and exploitation.

Acquisition refers to an organization's ability to identify and acquire externally generated knowledge that is critical 
to its operations (Zahra \& George, 2002, p. 189). The ability to acquire knowledge depends on the intensity, speed and direction of the organizational efforts to identify and collect information, which can determine the organization's knowledge quality: the larger the effort, the faster the organization can construct the required abilities.

Assimilation refers to the organization's routines and processes that allow it to analyze, process, interpret, and understand information acquired from external sources (Cohen \& Levinthal, 1990), e.g., when teachers use information that they have acquired from continuing academic studies in the framework of their professional role at the school.

Transformation is the internalization of new external knowledge in an existing organization's processes and products. This is accomplished by adding or deleting knowledge, or simply interpreting the same knowledge in a different manner (Leal-Rodríguez et al., 2014), e.g., when teachers use the knowledge they have gained to make changes in their work.

Finally, exploitation refers to how well an organization can exploit new external knowledge in its operations. It reflects the organization's ability to collect and integrate that knowledge into its activities and operations (Zahra \& George, 2002), e.g., when the knowledge teachers have gained enables them to develop the school's capabilities.

Professional development mechanisms and the acquisition of external knowledge allow teachers to construct their professional knowledge and tie it to their experiences through, for example, a joint examination of data on students' achievements, investing these achievements with meaning, developing an action plan based on the data, implementing it, and following up on this implementation (Kureland et al., 2010).

Research in the education domain has emphasized the importance of managing knowledge derived from external sources. For example, Honig (2003) suggested that organizational learning includes two processes: searching for information outside of the organization and using it within the organization's norms with respect to the behavior of organization members as individuals and the organization as a collective.

\subsection{The Relationship between PACAP and RACAP}

In the current study, we focus on these four dimensions as two capabilities of PACAP (acquisition and assimilation) and RACAP (transformation and exploitation). PACAP opens the organization to the acquisition and assimilation of externally generated knowledge (Lane \& Lubatkin, 1998). RACAP reflects the organization's capacity to leverage the knowledge that has been absorbed. Although PACAP and RACAP have different roles, their effects are not isolated, but rather complementary. Both subsets of ACAP coexist and contribute to the improvement of organization performance (e.g., Lane et al., 2006). Organizations cannot possibly exploit knowledge without first acquiring it. Similarly, organizations can acquire and assimilate knowledge but might not have the capability to transform and exploit it for profit generation. Thus, we argue that:

H1: Schools' ability to acquire and assimilate external knowledge (PACAP) will be positively related to their ability to transform and exploit this knowledge in their process (RACAP).

\subsection{Inspirational Vision Statements}

According to most researchers, outstanding leaders are typically described as being inspirational and visionary by their followers (Sosik \& Dinger, 2007). The literature on leadership (e.g., charismatic or transformational) appears to take visions as a given component of leadership that motivates people to higher levels of effort and performance (Berson et al., 2001). Empirical evidence from the last 20 years has shown that such leaders, through their understanding of the people and events around them, construct and deliver compelling statements that inspire followers to accept their vision of the future and behave accordingly (Sosik \& Dinger, 2007). A vision statement describes how the organization should look in the future (Orhan et al., 2014). The strategic management literature identifies the construction and delivery of vision statements as an important function of the organizational manager or business strategist, and as the first step in strategic planning (e.g., Berson et al., 2001). The vision statement has also been found to impact attitudes and performance of organizational members (e.g., Kirkpatrick \& Locke, 1996).

Berson et al. (2001) argued that the content (statement) of visions used by actual leaders either promotes radical transformation in their organizations or reinforces the direction that is already being pursued; the latter strategy is used when the leadership wants to maintain a high level of effort toward a certain goal over time. The vision's content is critical to determining whether a leader is successful in breaking out into new directions or maintaining high levels of continued success (Berson et al., 2001; Sosik \& Dinger, 2007).

In this study, we used earlier work on vision content by Berson et al. (2001), which defined a vision statement as an inspirational message to followers that expresses optimism about the future and confidence in meeting positive future 
challenges and opportunities, while highlighting the intrinsic needs that can be met, and connecting all of this to the core values of the organization. Researchers define strong vision content as inspiring (Berson et al., 2001); such inspiring visions have been associated with higher organizational performance and growth (e.g., Haque et al., 2016), and motivate followers to face difficult challenges (Berson et al., 2001).

\subsection{The Moderator Effect of Principals' Inspirational Vision Content on the Relationship between PACAP and RACAP}

Previous arguments have claimed that vision guides activities that bring about acquisition, assimilation, transformation and exploitation of knowledge, and provides individuals with rules or principles that will guide them in which knowledge to absorb and will determine the speed and intensity required for that acquisition (Waldman et al., 2005). Based on this, we suggest that those principals' vision statements that emphasize inspirational content will guide the change and exploitation of knowledge and will reduce the gap between their school's acquisition and assimilation abilities and their transformation and exploitation abilities (i.e., social integration mechanism).

Knowledge exploitation requires the sharing of relevant knowledge among members of an organization to promote mutual understanding and comprehension. Social integration mechanisms can facilitate the sharing and eventual exploitation of knowledge (Zahra \& George, 2002). We argue that the principals' inspirational vision statements give meaning and motivate organization members to reexamine their approach to routines, enable organization members to generate new connections between old and new knowledge, and garners their attention for the purpose of promoting information (Waldman et al., 2005).

Further, researchers have suggested that it is strongly advisable for the newly generated knowledge to be stored and maintained within the organization, thus facilitating accessibility for the organizational members who exploit it. Otherwise, RACAP and the valuable knowledge will be lost (Cepeda-Carrión et al., 2012). To effectively absorb and exploit knowledge, it is crucial to ensure the sharing of relevant knowledge among organizational members (Zahra \& George, 2002). Thus, we argue that inspirational visions unify teachers in knowledge sharing and in working together to achieve school goals. Thus, when teachers perceive the principal's vision content as inspirational, the school's ability to transform and exploit knowledge will be more significant. Therefore, we argue that:

H2: The relationship between PACAP and RACAP will be moderated by principals' inspirational vision content: the more the teachers perceive the principal's vision as optimistic, challenging and having intrinsic rewards, the stronger the positive association between the school's PACAP and RACAP.

\subsection{The Relationship between RACAP and Teacher Absenteeism}

Absence is defined as one's physical absence from work during a period defined as hours worked (Harrison et al., 2000). Absenteeism has been traditionally considered a major problem in human resource management (HRM) in a wide range of sectors and organizations (e.g., Rosenblatt et al., 2010). Teacher absenteeism can have negative effects on the entire school system, from lowering student achievement and attendance, to damaging the school's reputation and causing widespread economic losses (Rosenblatt et al., 2010).

We argue that RACAP has a long-term effect on school outcome (i.e., teacher absenteeism). Previous research examining long-term effects of ACAP argued that alignment between internal and external knowledge is critical to achieving a fit with a dynamic environment over time (Ben-Menahem et al., 2013). In one of the few studies that addressed changing ACAP over time, Popaitoon and Siengthai (2014) focused on HRM practices for 198 projects in multinational companies in the Thai automotive industry; they showed that the link between realized and potential ACAP depends on HRM practices that facilitate knowledge management from the current project to future ones. This strengthens the relationship between a project team's knowledge and long-term project performance. Others showed that external knowledge inflows are directly related to ACAP and indirectly related to innovation, but over different time spans (Kostopoulos et al., 2011).

ACAP depicts the school's ability to exploit and transform this knowledge-from teachers acquiring it from external resources, transforming it and exploiting it for the school process, thereby increasing the school's effectiveness - and the extent to which teachers can use and transform this external knowledge into internal knowledge to facilitate changes in the school and to increase its effectiveness.

The link between RACAP and teacher absenteeism has never been examined. As Zahra and George (2002) posited, despite the importance of PACAP, RACAP is the primary source of performance improvements. Thus, we suggest that teachers who are involved in the school learning process and make a comprehensive effort to transform and exploit the assimilated knowledge and use that knowledge in their daily work and in school processes, will perceive their job as less complicated; they will feel ownership of the organizational knowledge, and they will want to contribute to 
their school. As their work will thus be easier, their withdrawal behavior-such as absenteeism—will decrease approximately 1 year after the ACAP processes have been set into motion in their school.

Thus, our third hypothesis is that:

H3: The school's ability to transform and exploit knowledge in their process (RACAP) will be negatively related to teacher absenteeism 1 year after ACAP implementation.

\section{Methods}

\subsection{Participation and Procedures}

The participants in this study were 600 teachers and 100 principals from 100 Arab elementary schools in Northern Israel. To avoid common-source bias, we randomly selected 3 teachers from each school to report on leadership vision content, and 3 other teachers to rate ACAP. School principals provided demographic and school-background information. Among the teachers who participated in this study, $63 \%$ were female; teachers' mean age was 36 years $(\mathrm{SD}=8.9)$, mean tenure at their schools 9.8 years $(\mathrm{SD}=8.4)$, and mean period during which they worked with the principal 6.5 years $(\mathrm{SD}=6.2) ; 69 \%$ of the teachers had college degrees. All participants were assured that their responses would remain anonymous.

\subsection{Measures}

\subsubsection{ACAP}

We used a questionnaire developed by Da'as (2007), which has been validated in the educational system and captures the four dimensions of ACAP. This questionnaire contains 12 items, 3 items for each dimension. Teachers rated the 12 items on a 5-point scale: ( 1 - a little bit to 5 - a lot). An example item for acquisition was: "we use the knowledge we have gained from advanced academic studies" (inter-rater reliability alpha $=0.72$ ); for assimilation: "we use the knowledge gained while performing our professional duties at the school" (alpha $=0.89$ ); transformation: "The knowledge we have gained has made changes in our work as a teachers" (alpha $=0.90$ ); exploitation: "The knowledge we have gained enables us to develop the school's capabilities" (alpha $=0.86$ ). Alpha for the PACAP dimension was 0.78 and for the RACAP dimension, 0.88 .

Confirmatory factor analysis (CFA) was performed to examine the validity of PACAP and RACAP, using structural-equation modeling software AMOS 20. We used two common goodness-of-fit indices: comparative fit index (CFI) and root mean square error of approximation (RMSEA) (Byrne, 2006). The value of CFI ranges from 0 to 1 , and a CFI value $\geq 0.90$ is considered acceptable (good fit), while a value $>0.95$ is desirable. For RMSEA, values between 0.06 and 0.08 suggest an acceptable fit, while values $\leq 0.05$ indicate a close fit (Hu \& Bentler, 1999). For PACAP and RACAP, results indicated adequate fit to the data $(\mathrm{CFI}=0.96, \mathrm{RMSEA}=0.08$ and CFI $=0.98$, RMSEA $=0.06$, respectively) (Figure 2).

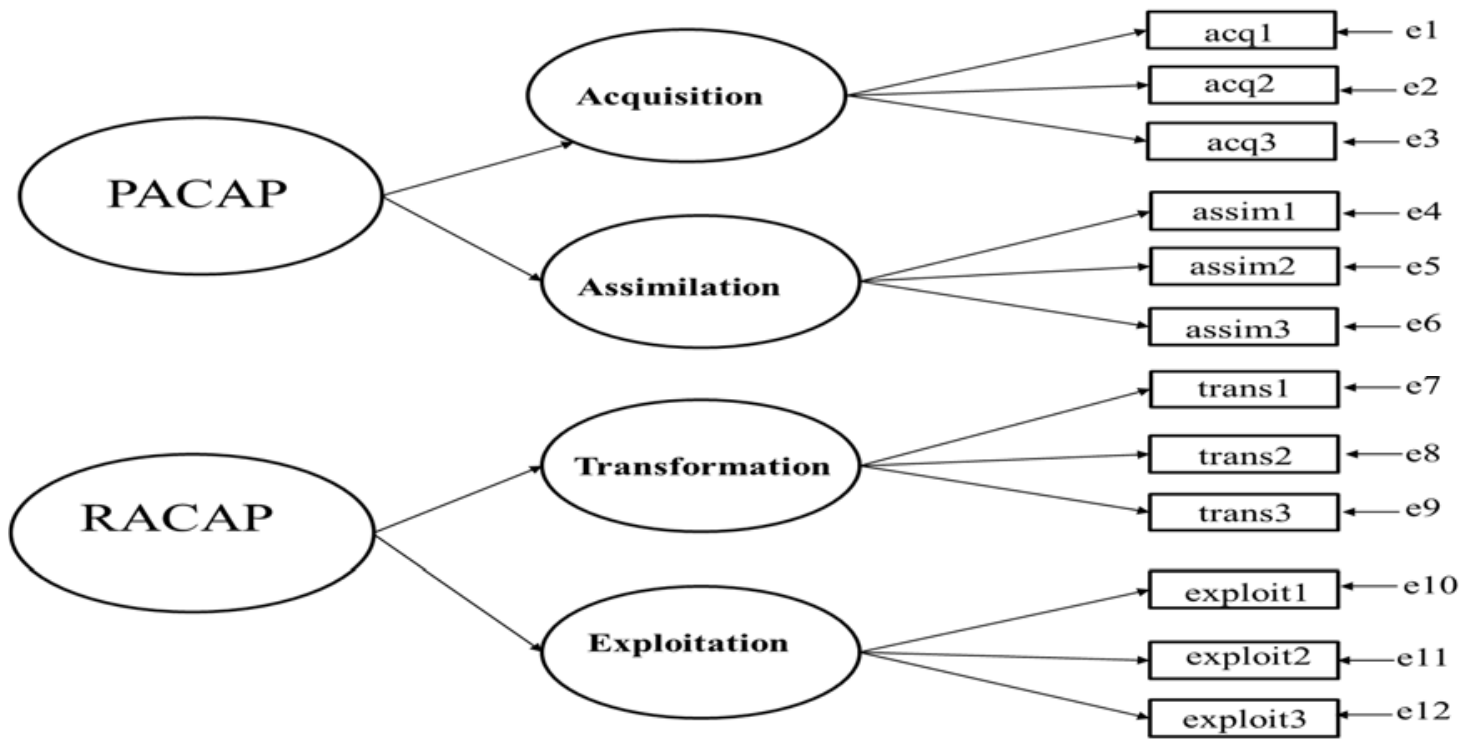

Figure 2. Factor Models to Measure PACAP and RACAP 
In the research hypotheses, the school is identified as the unit of analysis. Thus, we tested whether aggregation was appropriate using the rWG statistic (James et al., 1993), and by calculating the intra-class coefficients (ICC1 and ICC2; Bliese, 2000). ANOVA measures (ICCs) revealed significant F statistics for all of the dimensions of ACAP. As shown in Table 1, we found the average rWG to be over 0.77. The results of ICC1 and ICC2 (Table 1) provided sufficient statistical justification for aggregating ACAP to the group level (Bliese, 2000).

\subsubsection{Principals' Inspirational Vision Content}

We examined principals' inspirational vision content using 9 items from a measure designed by Berson et al. (2001) that describes inspirational vision content: optimism and confidence ( 2 items; alpha $=0.82)$, values and intrinsic rewards ( 4 items; alpha $=0.85)$, challenges and opportunities $(3$ items; alpha $=0.84)$. This scale assessed the extent to which team members consider school principals' vision content as inspirational (alpha $=0.85$ for the 3 vision factors). A sample item measuring optimism and confidence was: "Presents an optimistic picture of the future" (Berson et al., 2001). Teachers rated each item on a 5-point scale ranging from 1 - definitely not true to 5 - definitely true.

We found the average rWG to be over 0.79 for all factors of inspirational content. The results of ICC1 and ICC2 in Table 1, provided sufficient statistical justification for aggregating principals' vision content to the group level (Bliese, 2000).

Table 1. ICC, rWG and Reliability Alpha of Research Variables

\begin{tabular}{llll}
\hline Factor & ICC1 & ICC2 & rWG \\
\hline Optimism and confidence & .14 & .43 & .79 \\
Values and intrinsic rewards & .30 & .61 & .84 \\
Challenges and opportunities & .15 & .45 & .82 \\
Acquisition & .28 & .54 & .78 \\
Assimilation & .22 & .66 & .82 \\
Transformation & .20 & .65 & .83 \\
Exploitation & .23 & .57 & .86 \\
\hline
\end{tabular}

\subsubsection{Teacher Absenteeism}

Data were obtained from the educational system 1 year after the teachers had rated the ACAP and vision content. These data depict the number of days teachers were absent from the school per month (organizational level). Absenteeism was computed by calculating the total days of absence divided by the number of working days (for each school), from September to December. Researchers have used this annual division to examine changes in group absenteeism (for more details, see Mason \& Griffin, 2003).

\subsubsection{Controlled Variables}

We controlled for the effects of school size (i.e., number of teachers employed by the school) and principals' tenure in their jobs, because these variables are potentially relevant to outcomes such as organizational learning (Berson et al., 2015).

\section{Results}

Means, standard deviations, and correlations for the study variables are reported in Table 2.

Table 2. Means, Standard Deviations, and Correlations between Research Variables

\begin{tabular}{llllllll}
\hline & Mean & SD & $\mathbf{1}$ & $\mathbf{2}$ & $\mathbf{3}$ & $\mathbf{4}$ & $\mathbf{5}$ \\
\hline 1. PACAP (T1) & 4.02 & .33 & & & & & \\
2. RACAP (T1) & 4.15 & .41 & $.69^{* *}$ & - & & & \\
3. Principals' inspirational vision content (T1) & 3.90 & .48 & $.24^{*}$ & $.33^{* *}$ & - & & \\
4. Teacher absenteeism (T2) & 1.16 & .65 & $-.21^{*}$ & $-.25^{*}$ & $-.2^{*}$ & - & \\
5. Principals' tenure (T1) & 12.98 & 11.05 & .06 & .06 & .14 & .05 & \\
6. School size (T1) & 33.33 & 10.64 & .05 & .17 & .17 & .02 & -.14 \\
\hline
\end{tabular}

$\mathrm{N}=100 ;{ }^{* *} p<0.01$ (two-tailed); ${ }^{*} p<0.05$.


RACAP and PACAP were significantly related to the inspirational content of the principal's vision: $0.24-0.33$, and teachers' absenteeism was negatively related to RACAP.

We tested our hypotheses using the MPLUS program (Muthen \& Muthen, 2012). In our model, the moderator variable was considered a continuance variable. It is recommended that the independent and moderator variables be centered before calculating the product term. The product term should be significant in the regression equation for the interaction to be interpretable (Liu et al., 2017). Fitting our data to the hypothesized model (Figure 1) gave acceptable fit indices $\left(\chi^{2}(40)=54.50 ; p=\right.$ n.s.; $\mathrm{CFI}=0.97$; $\left.\mathrm{RMSEA}=0.06\right)$.

Figure 3 shows that the interaction between PACAP and principals' inspirational vision content for predicting RACAP was not significant $(\beta=-0.14 ; p=0.058)$, and therefore our second hypothesis was not confirmed. However, a strong relationship was found between PACAP and RACAP $(\beta=0.65 ; p<0.001)$, confirming our first hypothesis. Moreover, we found that RACAP negatively predicted teacher absenteeism 1 year later $(\beta=-0.259 ; p<0.01)$, thus confirming our third hypothesis. We also found a relationship between inspirational vision content and RACAP $(\beta=$ $0.13 ; p<0.05)$.

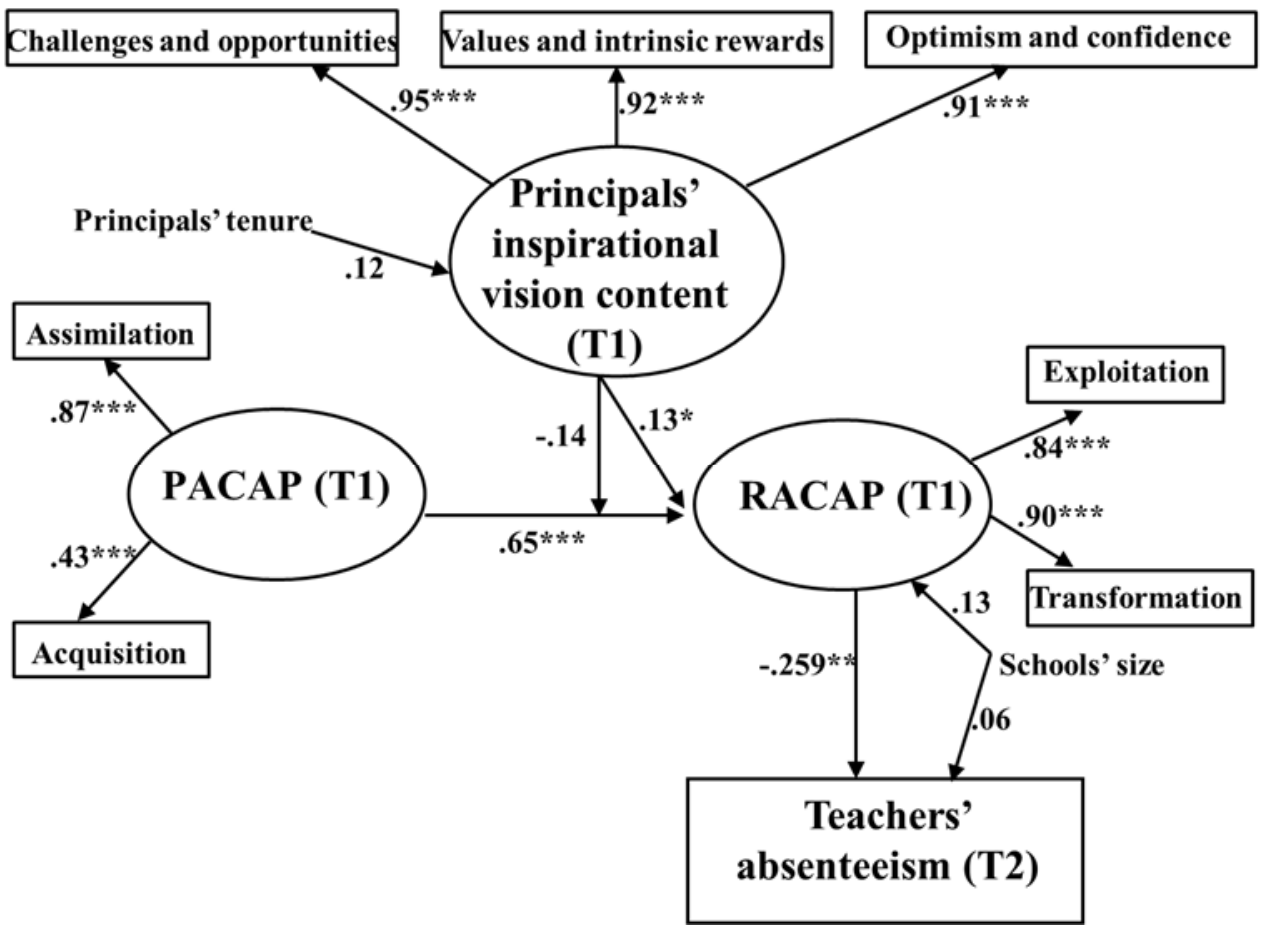

Figure 3. Results of the Hypothetical Model. Note: Standardized Estimates of Path Coefficients. ${ }^{*} p<0.05 ;{ }^{* *} p<$ $0.01 ; * * *<0.001$

We went on to examine the interaction graph by performing a simple slope analysis using an Excel spreadsheet that was designed by Jeremy Dawson: this worksheet plots two-way interaction effects for standardized variables (www.jeremydawson.co.uk/slopes.htm.), and tests the significance of the interaction slope. The graph in Figure 4 clearly shows that the interaction between principals' inspirational vision content and PACAP is not significant. We can see that there is a cutoff point between the high and low levels of inspirational vision content when PACAP is high. In this case, the value of high inspiration is 3.64, which is quite close to the low inspiration content value of 3.66. When the PACAP is low, the low inspirational content value is 2.08 , and the high value is 2.62 . 


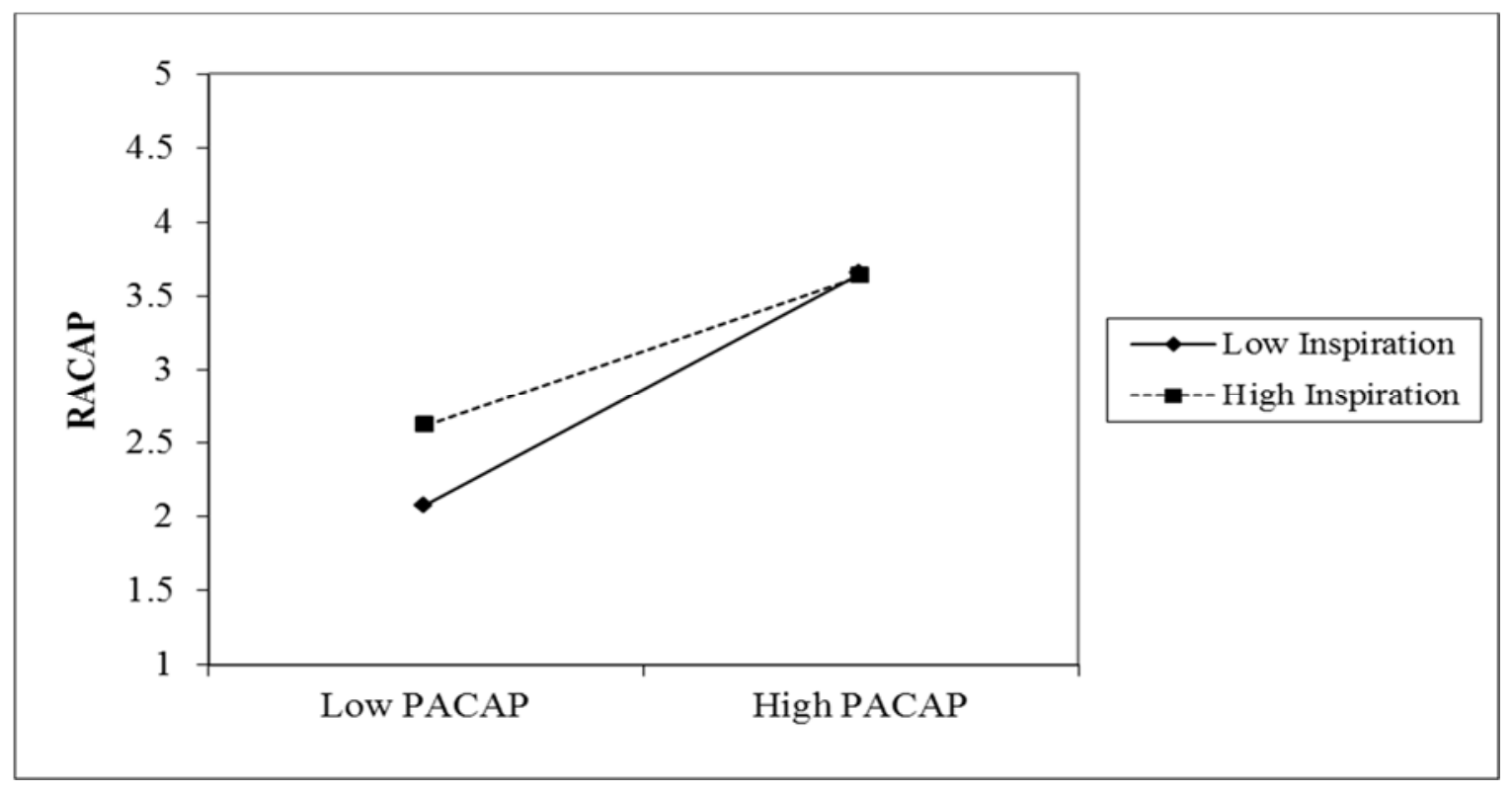

Figure 4. Interaction between Principals' Inspirational Vision Content and PACAP in Affecting RACAP

\section{Discussion}

Building upon the previous literature (Zahra \& George, 2002), this paper develops a research model that links PACAP, RACAP, principals' inspirational vision content and teachers' absenteeism. ACAP-in organizations in general but in the school context in particular - has become one of the most significant constructs in the last 20 years, precisely because external knowledge resources are so important to schools (Da'as, 2007; Zinkeviciene, 2004). Our study produced three important findings and opens avenues for further research into these mechanisms. The results showed that: (i) schools' PACAP has a strong effect on RACAP in the school setting; (ii) principals' inspirational vision content does not facilitate the relationship between PACAP and RACAP; (iii) RACAP reduces teacher absenteeism 1 year after its implementation.

The results of the current research show the strong impact of PACAP in promoting RACAP in a school setting. This result is in line with a recent study that found a direct relationship between the two in the business sector (Ali \& Park, 2016). Thus, the school's ability to acquire and assimilate knowledge from external sources affects its ability to transform this knowledge and exploit it for the school process, making it dynamic, effective and interactive. This capacity can enhance organizational efficiency. Schools can be considered as learning organizations, dealing with organizational knowledge to improve quality and management excellence (Da'as, 2007).

The results of the current research show that principals' inspirational vision content does not serve as a social integration mechanism, and it is not a condition for reducing the gap between RACAP and PACAP. This may lead to the conclusion that teachers' ACAP is affected by other social mechanisms. For many years, the innovation literature has suggested three primary contexts that can affect an organization's potential ACAP: (i) knowledge factors, (ii) relational factors, and (iii) institutional variables (Dougherty \& Hardy, 1996). For example, Leal-Rodríguez et al. (2014) identified additional variables as potentially affecting the knowledge-sharing processes: relational learning (i.e., information sharing, joint sense-making, and knowledge integration). Others have suggested variables such as power relationships (Todorova \& Durisin, 2007).

Another explanation for why principals' inspirational vision content did not serve as a social integration mechanism in the proposed ACAP model may lie in the teachers' perception of it as an essential trait for school principals that does not positively influence ACAP components. Furthermore, our study did not consider the extent to which the vision is shared in the schools. Studies have argued that vision and missions should not simply be described; the statements need to be learned, adopted and exercised by the employees (Stovel \& Bontis, 2002). Aydemir (2000) highlights the importance of sharing visions in organizations to develop learning organizations. In this regard, Zinkeviciene (2004) focused on the school's culture of collaboration to promote ACAP. Another study, found that leadership strategies (i.e., shared goal setting, ongoing curriculum revision, and teacher collaboration) and coherence 
allow leaders and educators to assimilate, transform, and create new knowledge in ways that provide absorptive capacity and allow for selective implementation of disruptive innovations (Zuckerman et al., 2018).

A further result of the current research related to the effect of principals' inspirational vision content on RACAP. This is in line with previous studies relating school principals with organizational learning (Berson et al., 2015). Specifically, school teachers who perceived the principal's vision as optimistic, inspirational, and presenting challenges and opportunities, were more likely to create something new based on the "transformed" knowledge.

RACAP plays an important role in the exploitation of new knowledge and ultimately helps the school create value by reducing teacher absenteeism a year after its establishment. Teachers' who are involved in the school learning process and make a comprehensive effort to transform and exploit the assimilated knowledge and use that knowledge in their daily work and in school processes, will increase schools' ACAP ability, which lead to school's effectiveness.

This is an important theoretical contribution in that RACAP has the potential to minimize teacher absenteeism; it contributes to the small number of studies that have found correlations between the four dimensions of ACAP and school effectiveness, such as, ACAP and organizational affective commitment (Da'as, 2007), and to those that have focused on developing school capability (ACAP) in pedagogical innovation (Zinkeviciene, 2004).

The results on the relationship between RACAP and teacher absenteeism extend the notion of a long-term effect. Zahra and George (2002), who distinguished between an organization's potential and realized ACAP, suggested that while the latter provides a short-term benefit, reflecting exploitation of existing knowledge, PACAP is a dynamic capability and may therefore be more useful for adapting to the environment. This suggests that organizations may get a short-term benefit from external acquisition but need to build longer-lasting benefits through a combination of internal and external knowledge.

Future research should explore the roles of other social integration mechanisms in PACAP and RACAP, in the school setting. These could be leadership style (e.g., charismatic leadership; Berson et al., 2015), skills, leadership strategies (Zuckerman et al., 2018), and values. Previous theoretical research has emphasized leadership style in promoting ACAP (Phoocharoon, 2015). Another social mechanism might be the type of knowledge. Todorova and Durisin (2007) argued that social integration mechanisms influence all components of ACAP and that the influence can be either negative or positive, depending on the type of new knowledge and the type of knowledge processes. Becker and Peters (2000) argued that organizations need higher ACAP for scientific vs. other types of knowledge. Schools also need to acquire and assimilate different types of knowledge (i.e., pedagogical). Therefore, knowledge types should be examined with respect to reducing the gap between PACAP and RACAP. Finally, future research might explore this challenging question: Can RACAP play a mediating role between PACAP and long-term school outcomes (e.g., teacher absenteeism)?

This study has several limitations. The first is the use of teacher absenteeism as a measure of outcomes instead of student achievement. In the Israeli educational system, data on student achievements are gathered once every 4 years in each of the four core subjects. Furthermore, there are differences between schools in the specific subjects tested every year. Therefore, we suggest conducting wide research to examine other objective outcomes, such as innovative behavior or student achievement.

This study, like Zahra and George (2002), looked at the dimensions of ACAP as only PACAP and RACAP. Other researchers have considered ACAP to have four dimensions, with no overlap between them (e.g., Todorova \& Durisin, 2007). Furthermore, Todorova and Durisin (2007) argued that the contingency factor of social integration must influence not only transformation but also the other components of ACAP. Thus, future study will focus on the effect of social integration mechanisms on the separate dimensions.

\subsection{Implications for Practice}

The results of this study emphasize the importance of school PACAP and RACAP in reducing teacher absenteeism. Therefore, school principals and the Ministry of Education have to emphasize these processes as an important priority in schools. We suggest that the government elect to implement selection/training procedures for current and prospective principals that will take into consideration the important role of ACAP in schools. A more specific program might be designed to train leaders in acquiring and utilizing skills to promote ACAP in schools, specifically, to encourage teachers to acquire external knowledge which is relevant to their work and their professional subject, in order to increase school's effectiveness, so as to reduce absences from work.

Furthermore, school principals have to emphasize the essential role of inspirational vision statements in promoting RACAP; this, in turn, will reduce teacher absenteeism, which is considered a big challenge for educational systems and principals. 
This research also contributes to school principals' promotion of ACAP toward building a positive workplace culture, in which teachers can incorporate the knowledge they acquire from external resources into the school's structures and routines.

Further, the policymakers of the educational system have to encourage teachers acquiring external knowledge by opening more development professional courses, funding by them. This allowed schools to maintain high levels of effectiveness in the face of disruptive policy innovations. Zuckerman et al., (2018) argued that for rural schools, absorptive capacity may provide a means to buffer external policy changes by providing opportunities to assimilate and transform new knowledge into existing practices, rather than replacing them with standardized practices (p.4).Finally, this study opens new research avenues for the exploration of social integration mechanisms between RACAP and PACAP, and for examining the effects of ACAP in school settings. It is also important in providing a better understanding of the effectiveness of potential and realized ACAP for school outcomes, and the specific integration mechanisms that affect different relative levels of potential and realized ACAP in schools.

\section{References}

Ali, M., \& Park, K. (2016). The mediating role of an innovative culture in the relationship between absorptive capacity and technical and non-technical innovation. Journal of Business Research, 69(5), 1669-1675. https://doi.org/10.1016/j.jbusres.2015.10.036

Aydemir, N. (2000). Öğrenen organizasyonların oluşturulmasında vizyon paylaşımı. İktisat, İşletme ve Finans, 15(168), 27-34. https://doi.org/10.3848/iif.2000.168ek.1364

Becker, W., \& Peters, J. (2000). Technological opportunities, absorptive capacities, and innovation. Discussion Paper Series 195, Universitaet Augsburg, Institute for Economics.

Ben-Menahem, S. M., Kwee, Z., Volberda, H. W., \& Van Den Bosch, F. A. J. (2013). Strategic renewal over time: the enabling role of potential absorptive capacity in aligning internal and external rates of change. Long Range Plan, 46(3), 216-235. https://doi.org/10.1016/j.lrp.2012.09.012

Berson, Y., Da'as, R., \& Waldman, D. A. (2015). How do leaders and their teams bring about organizational learning and outcomes? Personnel Psychology, 68(1), 79-108. https://doi.org/10.1111/peps.12071

Berson, Y., Shamir, B., Avolio, B. J., \& Popper, M. (2001). The relationship between vision strength, leadership style, and context. The Leadership Quarterly, 12(2), 53-73. https://doi.org/10.1016/S1048-9843(01)00064-9

Bliese, P. D. (2000). Within-group agreement, non-independence, and reliability: implications for data aggregation and analysis. In K. J. Klein, S. W. J. Kozlowski (Eds.), Multilevel theory, research, and methods in organizations: foundations, extensions, and new directions (pp. 349-381). San Francisco, CA: Jossey-Bass.

Byrne, B. M. (2006). Structural equation modeling with EQS: basic concepts, applications, and programming (2nd ed.). Mahwah, NJ: Lawrence Erlbaum Associates.

Cassiman, B., \& Veugelers, R. (2002). Complementarity in the innovation strategy: internal R\&D, external technology acquisition, and cooperation in R\&D. https://doi.org/10.2139/ssrn.303562

Cepeda-Carrión, G., Cegarra-Navarro, J. G., \& Jimenez-Jimenez, D. (2012). The effect of absorptive capacity on innovativeness: context and information systems capability as catalysts. British Journal of Management, 23, $110-129$.

Cohen, W., \& Levinthal, D. (1990). Absorptive capacity: a new perspective on learning and innovation. Administrative Science Quarterly, 35, 128-152. https://doi.org/10.2307/2393553

Da'as, R. (2007). The relationship between shared vision, organizational learning and the conception of school performance (Hebrew). University of Haifa, Israel.

Dougherty, D., \& Hardy, C. (1996). Sustained product innovation in large mature organizations: overcoming innovation to organization problems. Academy of Management Journal, 39(5), 1120-1153. https://doi.org/10.2307/256994

Easterby-Smith, M., \& Lyles, M. (2003). Re-Reading" Organizational Learning": Selective Memory, Forgetting, and Adaptation. The Academy of Management Executive (1993-2005), 51-55. https://doi.org/10.5465/AME.2003.10025192

Easterby-Smith, M., Graça, M., Antonacopoulou, E., \& Ferdinand, J. (2008). Absorptive capacity: A process 
perspective. Management learning, 39(5), 483-501. https://doi.org/10.1177/1350507608096037

Gbore, L. O., \& Daramola, C. A. (2013). Relative contributions of selected teachers' variables and students attitude toward academic achievement in biology among senior secondary school students in Ondo State, Nigeria. Current Issues in Education, 16(1).

Haque, M., TitiAmayah, A., \& Liu, L. (2016). The role of vision in organizational readiness for change and growth. Leadership \& Organizational Development Journal, https://doi.org/10.1108/LODJ-01-2015-0003

Harrison, D. A., Johns, G., \& Martocchio, J. J. (2000). Changes in technology, teamwork, and diversity: new directions for a new century of absenteeism research. Research in Personnel and Human Resources Management, 18, 43-92.

Honig, M. I. (2003). Building policy from practice: district central office administrators' roles and capacity for implementing collaborative education policy. Educational Administration Quarterly, 39, $292-338$. https://doi.org/10.1177/0013161X03253414

Hu, L., \& Bentler, P. M. (1999). Cutoff criteria for fit indexes in covariance structure analysis: convention criteria versus new alternatives. Structural Equation Modeling, 6(1), 1-55. https://doi.org/10.1080/10705519909540118

James, L., Demaree, R. G., \& Wolf, G. (1993). rwg: an assessment of within-group interrater agreement. Journal of Applied Psychology, 78, 306-309. https://doi.org/10.1037/0021-9010.78.2.306

Kang, M., \& Lee, M. J. (2017). Absorptive capacity, knowledge sharing, and innovative behaviour of R\&D employees. Technology Analysis \& Strategic Management, 29(2), 219-232. https://doi.org/10.1080/09537325.2016.1211265

Khan, F., Xuehe, Z., Atlas, F., Khan, K., Pitafi, A., \& Saleem, M. (2017). Impact of absorptive capacity and dominant logic on innovation performance of public sector organizations in Hefei (Anhui Province), China. Management Science Letters, 7(6), 275-284. https://doi.org/10.5267/j.msl.2017.3.004

Kirkpatrick, S., \& Locke, E. (1996). Direct and indirect effects of three core charismatic leadership components on performance and attitudes. Journal of Applied Psychology, 84(1), 36-51. https://doi.org/10.1037/0021-9010.81.1.36

Kostopoulos, K., Papalexandris, A., Papachroni, M., \& Ioannou, G. (2011). Absorptive capacity, innovation, and financial performance. Journal of Business Research, 64(12), $1335-1343$. https://doi.org/10.1016/j.jbusres.2010.12.005

Kurland, H., Peretz, H., \& Hertz-Lazarowitz, R. (2010). Leadership style and organizational learning: The mediate effect of school vision. Journal of Educational Administration, 48(1), 7-30. https://doi.org/10.1108/09578231011015395

Lane, P. J., \& Lubatkin, M. (1998). Relative absorptive capacity and interorganizational learning. Strategic

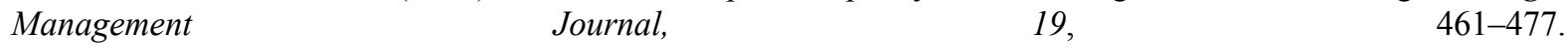
https://doi.org/10.1002/(SICI)1097-0266(199805)19:5\%3C461::AID-SMJ953\%3E3.0.CO;2-L

Lane, P. J., Koka, B., \& Pathak, S. (2006). The reification of absorptive capacity: a critical review and rejuvenation of the construct. The Academy of Management Review, 31(4), 833-863. https://doi.org/10.5465/AMR.2006.22527456

Leal-Rodríguez, A. L., Roldán, J. L., Ariza-Montes, J. A., \& Leal-Millán, A. (2014). From potential absorptive capacity to innovation outcomes in project teams: The conditional mediating role of the realized absorptive capacity in a relational learning context. International Journal of Project Management, 32(6), 894-907. https://doi.org/10.1016/j.ijproman.2014.01.005

Liu, Y., West, S. G., Levy, R., \& Aiken, L. S. (2017). Tests of simple slopes in multiple regression models with an interaction: comparison of four approaches. Multivariate Behavioral Research, 52(4), 445-464. https://doi.org/10.1080/00273171.2017.1309261

Mason, C. M., \& Griffin, M. A. (2003). Group absenteeism and positive affective tone: a longitudinal study. Journal of Organizational Behavior, 24(6), 667-687. https://doi.org/10.1002/job.210

Miller, R. T., Murnane, R. J., \& Willett, J. B. (2008). Do teacher absences impact student achievement? Longitudinal evidence from one urban school district. Educational Evaluation and Policy Analysis, 30(2), 181. 
https://doi.org/10.3102/0162373708318019

Mulford, B., \& Silins, H. (2011). Leadership for Organisational Learning and Improved Student Outcomes-What Do We Know?. International Journal of Educational Management, 25(1), 61-82. https://doi.org/10.1108/09513541111100125

Muthen, L. K., \& Muthen, B. O. (2012). Mplus version 7 user's guide (7th ed.). Los Angeles, CA: Muthen \& Muthen.

Orhan, G., Erdoğan, D., \& Durmaz, V. (2014). Adopting mission and vision statements by employees: the case of TAV airports. Procedia-Social and Behavioral Sciences, 150, 251-262. https://doi.org/10.1016/j.sbspro.2014.09.051

Phoocharoon, P. (2015). Transformational leader in action of energizing absorptive capacity through organizational routines and capabilities. International Journal of Innovation, Management and Technology, 6(5), 332-338. https://doi.org/10.18178/ijimt.2015.6.5.625

Popaitoon, S., \& Siengthai, S. (2014). The moderating effect of human resource management practices on the relationship between knowledge absorptive capacity and project performance in project-oriented companies. International Journal of Project Management, 32(6), 908-920. https://doi.org/10.1016/j.ijproman.2013.12.002

Rosenblatt, Z., Shapira-Lishchinsky, O., \& Shirom, A. (2010). Absenteeism in Israeli schoolteachers: an organizational ethics perspective. Human Resource Management Review, 20(3), 247-259. https://doi.org/10.1016/j.hrmr.2009.08.006

Saraf, N., Liang, H., Xue, Y., \& Hu, Q. (2013). How does organisational absorptive capacity matter in the assimilation of enterprise information systems? Information Systems Journal, 23(3), 245-267. https://doi.org/10.1111/j.1365-2575.2011.00397.x

Sosik, J. J., \& Dinger, S. L. (2007). Relationships between leadership style and vision content: the moderating role of need for social approval, self-monitoring, and need for social power. The Leadership Quarterly, 18(2), 134-153. https://doi.org/10.1016/j.leaqua.2007.01.004

Stokely, C. R. (2004). Getting everybody on the same page. Handbook of Business Strategy, 5(1), 171-172. https://doi.org/10.1108/10775730410494279

Stovel, M., \& Bontis, N. (2002). Voluntary turnover: knowledge management friend or foe? Journal of Intellectual Capital, 3(3), 303-322. https://doi.org/10.1108/14691930210435633

Todorova, G., \& Durisin, B. (2007). Absorptive capacity: valuing a reconceptualization. Academy of Management Review, 32(3), 774-786. https://doi.org/10.5465/AMR.2007.25275513

Volberda, H. W., Foss, N. J., \& Lyles, M. A. (2010). Perspective-absorbing the concept of absorptive capacity: how to realize its potential in the organization field. Organization Science, 21(4), 931-951. https://doi.org/10.1287/orsc.1090.0503

Waldman, D. A., Berson, Y., \& Pearce, C. L. (2005). Toward an understanding of shared vision and organizational learning: the complementary roles of vertical and shared leadership. Paper presented at the Academy of Management, Honolulu, HI.

Zahra, S. A., \& George, G. (2002). Absorptive capacity: a review, reconceptualization, and extension. Academy of Management Review, 27(2), 185-203.

Zinkeviciene, N. (2004). How to examine educational organization absorptive capacity in the aspect of pedagogical innovations? Paper presented at the European Conference on Educational Research Post Graduate and New Researcher Pre-Conference. Retrieved from http://www.leeds.ac.uk/educol/documents/00003795.htm

Zollo, M., \& Winter, S. G. (2002). Deliberate learning and the evolution of dynamic capabilities. Organization science, 13(3), 339-351. https://doi.org/10.1287/orsc.13.3.339.2780

Zuckerman, S.J., Campbell Wilcox, K., Schiller, K.S., \& Durand, F.T. (2018). Absorptive capacity in rural schools: Bending not breaking during disruptive innovation implementation. Journal of Research in Rural Education, $34(3), 1-27$. 